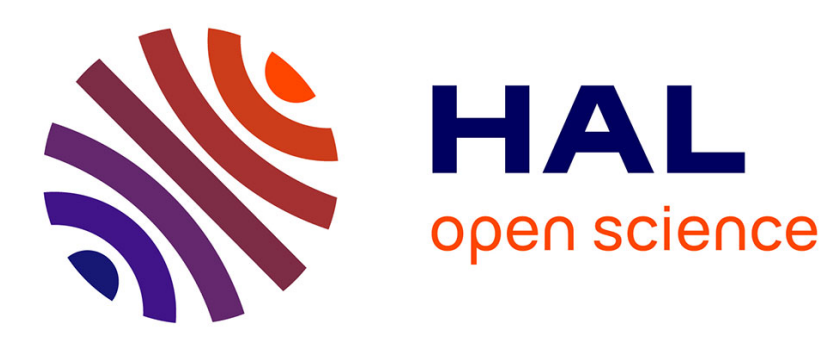

\title{
Polymer tracer detection systems with UV fluorescence spectrometry to improve product reyclability
}

\author{
Elizabeth Maris, Améziane Aoussat, E. Naffrechoux, Daniel Froelich
}

\section{To cite this version:}

Elizabeth Maris, Améziane Aoussat, E. Naffrechoux, Daniel Froelich. Polymer tracer detection systems with UV fluorescence spectrometry to improve product reyclability. Minerals Engineering, 2012, 29, pp.12. 10.1016/j.mineng.2011.09.016 . hal-01202756

\section{HAL Id: hal-01202756 \\ https://hal.science/hal-01202756}

Submitted on 21 Sep 2015

HAL is a multi-disciplinary open access archive for the deposit and dissemination of scientific research documents, whether they are published or not. The documents may come from teaching and research institutions in France or abroad, or from public or private research centers.
L'archive ouverte pluridisciplinaire $\mathbf{H A L}$, est destinée au dépôt et à la diffusion de documents scientifiques de niveau recherche, publiés ou non, émanant des établissements d'enseignement et de recherche français ou étrangers, des laboratoires publics ou privés. 


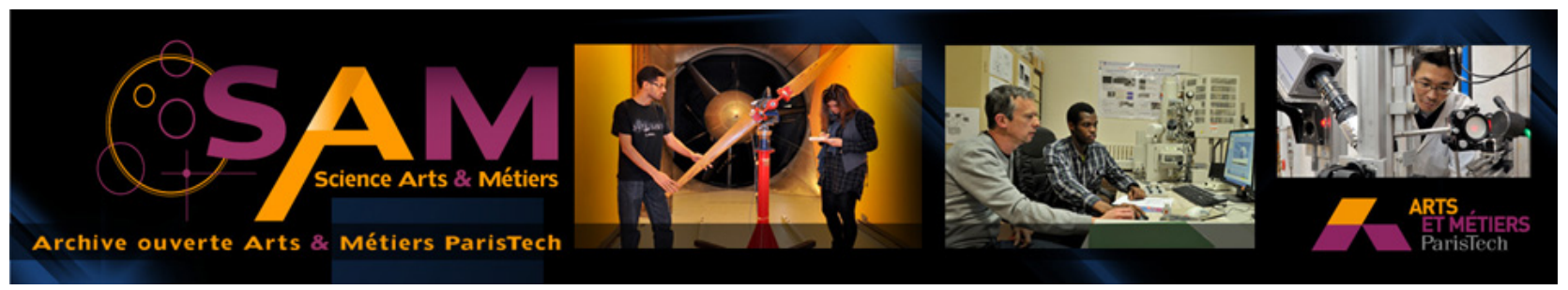

Science Arts \& Métiers (SAM)

is an open access repository that collects the work of Arts et Métiers ParisTech researchers and makes it freely available over the web where possible.

This is an author-deposited version published in: http://sam.ensam.eu

Handle ID: .http://hdl.handle.net/10985/10087

\section{To cite this version :}

Elizabeth MARIS, Améziane AOUSSAT, Emmanuel NAFFRECHOUX, Daniel FROELICH Polymer tracer detection systems with UV fluorescence spectrometry to improve product reyclability - Minerals Engineering - Vol. 29, p.12 - 2012 


\title{
Polymer tracer detection systems with UV fluorescence spectrometry to improve product recyclability
}

\author{
E. Maris ${ }^{\mathrm{a}, *}$, A. Aoussat ${ }^{\mathrm{b}}$, E. Naffrechoux $^{\mathrm{c}}$, D. Froelich ${ }^{\mathrm{a}}$ \\ a Laboratoire Conception Produit Innovation, Chambéry (LCPI), Institut ARTS et METIERS ParisTech Chambéry, Savoie Technolac, 4 Rue du Lac Majeur, F-73 375 Le Bourget \\ du Lac Cedex, France \\ ${ }^{\mathrm{b}}$ LCPI, ARTS et METIERS ParisTech Paris, France \\ ${ }^{\mathrm{c}}$ Laboratoire Chimie Moléculaire Environnement (LCME), Université de Savoie, F-73 376 Le Bourget du Lac, France
}

Keywords:

Automatic sorting

Crushed polymer waste

Tracer

UV fluorescence

Recyclability

\begin{abstract}
A B S T R A C T
The recycling of materials originating from end-of life products is essential to preserve our raw material resources, which are increasingly expensive and whose extraction is increasingly impactful for the environment. However, certain materials are still not recycled today. In the case of plastics, their recycling includes grinding, which generates complex mixtures. It is not possible to sort these mixtures and reach a high degree of purity with the existing physico-chemical processes. Automated sorting processes using near infrared spectroscopy are limited to dark-colored materials. One option is to add tracers to virgin materials to allow identification and rapid sorting of end-of-life products, using UV fluorescence spectrometry as the identification technique. The optimization of the polymer/tracer/detection system is based on several criteria: the reliability and speed of detection of UV fluorescence tracers added to a polymer matrix with carbon black, the relevance of the environmental impact of the tracers, and the preservation of the mechanical properties of the polymer with the tracers added.
\end{abstract}

\section{Introduction}

Certain oil and mineral resources are becoming increasingly rare and expensive to extract, and their extraction has increasingly serious environmental impacts on both the ecosystem and human health. As many studies have shown, improving a product's recyclability is one of the ways to limit environmental impacts and material costs. The production of recycled materials makes it possible to save over $80 \%$ in energy in comparison with that required for virgin materials (Fig. 1), and to avoid considerable greenhouse gas emissions.

Despite the development of product eco-design (Millet, 2003; Tonnelier et al., 2007) and the improvement of recycling technologies, polymers are recycled very little today. Why? Firstly, crushing processes produce complex mixtures. It is not possible to sort these complex mixtures and achieve high purity rates with the existing physico-chemical methods (Reuter et al., 2006), and spectrometric methods do not allow the sorting of dark-colored polymer materials. In 2009, 24.3 Mtons of plastic waste were generated in Europe, and only $22.5 \%$ on average were recycled in all sectors combined (PlasticsEurope, 2010).

The presence of impurities in the polymers due to poor sorting quality impacts the performance of the recycled material. Good

\footnotetext{
* Corresponding author.

E-mail address: elisabeth.maris@ensam.eu (E. Maris).
}

recycled material quality is required in order to find "noble" outlets and expand the number of opportunities to use a high-performance, safe material with an economic value close to that of virgin plastics.

Finally, in today's context, many mass consumption products escape collection or are treated in medium-sized facilities. Mass quantities of recycled plastics are not available. It is therefore necessary to find compromises between the sorting level (by matrix, by additive, etc.), the properties and the volumes generated in order to meet the demands of the key players in the market.

To overcome these technological limitations, one possibility is to add specific tracers to polymer families to facilitate their rapid, automated industrial sorting using UV fluorescence spectrometric sorting. The research problematic is to determine the criteria for selecting the polymer candidates for recycling and detection conditions in line with the choice of tracers.

In 2008, a first study entitled TRITRACE focusing on the detection of tracers in colorless and black polypropylene and white ABS was carried out with the industrial partners SEB Group, Plastic Omnium, and Tracing Technologies, and two laboratories, the ITECH and the ARTS et METIERS ParisTech Institute in Chambery. Two patents (Lambert and Hachin, 2010a,b) were registered. The study was continued in 2010 though a program financed by the French National Research Agency (ANR) and expanded to include other tracers and polymer families.

The initial results of these two projects are discussed in this paper. A description of the polymer tracing process for recycling 


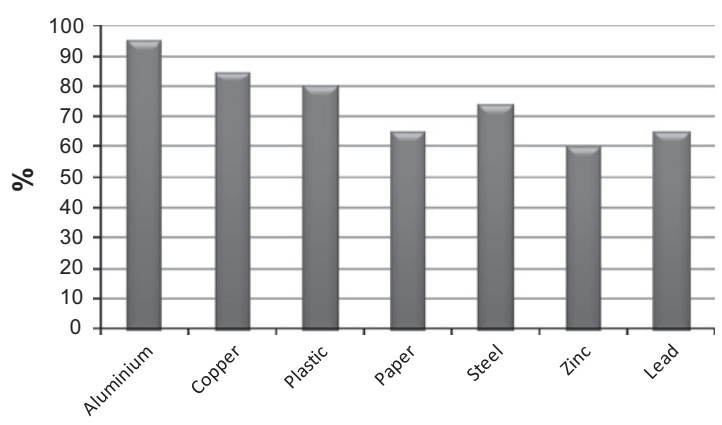

Fig. 1. The use of recycled material saves energy compared to the use of virgin material (BIR, 2009).

is presented with a state of the art of the tracing techniques used for recycling. The concept of tracing for the purposes of material recycling was defined and experimented. The approach of this study consisted of different steps: firstly to define the appropriate polymer candidates, secondly to determine the tracers according to the number of polymers chosen and according to technical criteria such as the intensity of the light sources available enabling tracer excitation and the sensitivity and speed of the detection systems receiving the fluorescence signals. Two polymers containing two tracers and two white and black colorants were tested. Tests results were conducted to validate fluorescence detection and the mechanical preservation of properties before and after aging of the samples in accordance with the specifications of the automotive and household appliance sectors.

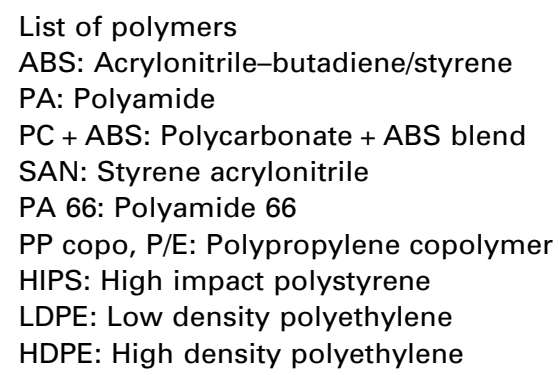

\section{Description of the polymer tracing process for recycling}

\subsection{Bibliographical research}

Several studies have been published on tracing technologies for polymers recycling. The development of the concept of a virgin polymer tracing system for sorting began in 1993. The first patent registered (British Petroleum Company, 1993) describes a method to identify polymers by detecting the fluorescence of certain tracers composed of rare earths in the near-infrared spectral range (NIR) between 700 and $900 \mathrm{~nm}$ for tracer concentrations from $0.001 \mathrm{ppm}$ to $1 \mathrm{ppm}$. The source used is a laser diode emitting in the NIR at $670 \mathrm{~nm}$. The disadvantage of this method is its difficulty to detect a signal in the NIR when the matrix has a dark color. The carbon black used as a colorant absorbs all of the rays in the NIR (Eisenreich et al., 1992).

A patent registered in 1994 (Bayer, 1994) describes two tracer systems with different fluorescence emission wavelengths, with tracers with different fluorescence durations for each system. The identification principle allows codification with four tracers. This method is currently used in the biochemical sector. The experi- mental system includes a flash lamp and a programmable camera to defer the shooting of the image by a few nano-seconds after excitation by the source. This system thus enables the identification of molecules that have the same fluorescence emission wavelength but not the same duration. This method appears difficult to install in a rapid, automated sorting system, since with industrial systems there is continuous light on the samples to be sorted, making it impossible to differentiate the fluorescence durations in order to differentiate the tracers.

In 1998, another study (Simmons et al., 1998) (Ahmad, 2004) financed by a European program led to a first pilot system to sort plastic bottles in the packaging sector. With this system, thanks to a codification based on combinations of three tracers with concentrations raging between 0.5 and $20 \mathrm{ppm}$, it was possible to identify bottles made with PEHD. Patents for this identification system were registered by the program partners (Lambert and Hachin, 2004). The pilot bench did not enable the identification of dark-colored tracers, and no test was carried out on other types of polymer matrixes.

In 2007, a study was carried out on the state of the art of the different tracing technologies (Froelich et al., 2007a,b). Two technologies were validated to sort black polypropylene: magnetic tracer detection and $\mathrm{X}$ ray fluorescence detection of tracers made from rare earths. In 2008, a thesis was financed by the French Environment and Energy Management Agency (ADEME) to conduct laboratory tests on X fluorescence detection (Bezati et al., 2010). The results of this research showed that detection with magnetic tracers is industrially viable but does not allow codification with several tracers. $X$ fluorescence detection enables the detection of tracers based on rare earth oxides at concentrations of $1000 \mathrm{ppm}$ in black or painted polymers. The absorption of the $\mathrm{X}$ fluorescence by the molecules of the ambient air makes it impossible to decrease the concentrations of tracers to below $100 \mathrm{ppm}$, and detection times are still long with respect to the industrial constraints of rapid sorting. The choice of tracers is limited to rare earths.

In conclusion, all of these different studies validated the polymer tracing technique. Certain aspects of the fluorescence of polymer tracer systems must be explored in further depth, such as possible signal attenuation phenomena due to the interaction between tracers, polymers and their additives such as carbon black, the influence of polymer aging on fluorescence, and the choice of tracers with a lesser impact on natural resources.

\subsection{The concept of material tracing for recycling}

This technique makes it possible to identify a material thanks to the signature of a tracer and not its intrinsic properties, and is already used to authenticate objects such as banknotes.

Polymer tracing consists of incorporating into a material a small concentration of a substance with specific luminescence properties after irradiation by a light source, and carrying out a spectrometric analysis of the signal of the substances incorporated in the material in order to identify them according to the positive or negative signal (Fig. 2).

The concept of polymer tracing for recycling is different from that of the marking of polymer parts in accordance with ISO 11469 2000: "Generic identification and marking of products made of plastic materials". Following this standard, new parts are engraved with a code enabling the identification of their materials, in order to recycle parts after manual sorting.

The polymers that are candidates for tracing are those recognized as difficult to sort with the current physico-chemical sorting or optical sorting technologies. They are essentially polymers that are dark-colored and have similar densities, or that have fillers that 


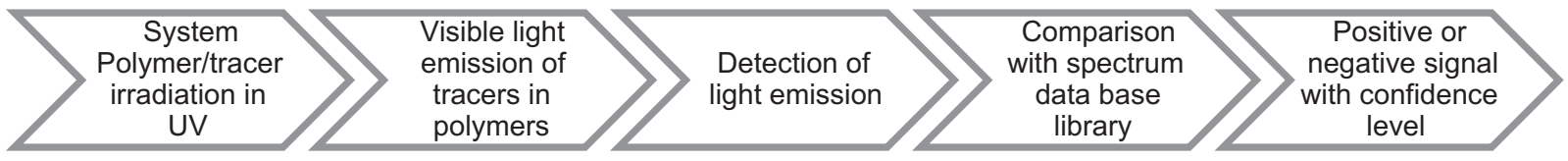

Fig. 2. Flow diagram of the detection of polymers marked with tracers.

modify their density and when combined are incompatible for recycling (Froelich et al., 2007a,b).

The tracers are incorporated during the compounding phase, when all additives such as anti-UV agents and stabilizers are added (see Fig. 3).

\section{Approach}

To confirm that the tracer sorting technology is viable, several steps are required: choosing the polymers to be traced, choosing the tracers and choosing the detection system.

\begin{tabular}{|c|c|c|}
\hline $\begin{array}{c}\text { Priority choice of material for } \\
\text { recycling }\end{array}$ & $\begin{array}{c}\text { Choice of tracers: Cost toxicity, } \\
\text { polymer compatibility, impact } \\
\text { on resources }\end{array}$ \\
automated sorting: velocity \\
$10 \mathrm{~ms}$
\end{tabular}

The incorporation of tracers in polymers can only be viable at the European scale, provided that a European directive and a standard for tracer incorporation procedures are decided upon. Certain immediate applications are possible, such as the marking of labeled materials or products. The difficulty in Europe is not only technological, but regulatory.

During a product's usage phase, the tracers must not modify material properties or deteriorate during the product's lifetime.

Tracing technology can be integrated in the current treatment path for used products (Fig. 4). The plastic fraction is extracted from the other fractions and represents a complex mixture of crushed particles. The polymers are identified using a spectroscopic detection process. The plastics are irradiated with a UV source and detection is carried out in the visible spectrum. The polymers are identified and sorted according to each polymer's identity code (Fig. 5).

During the recycling phase, the quantity of tracer is controlled and topped up along with the quantity of additives usually added, i.e. anti-UV agents, antioxidants, etc. (Fig. 6).

\subsection{Choosing the polymers to be traced}

Measurements made on samples taken after crushing show that black-colored polymers account for the majority in the automotive sector and represent up to $40 \%$ in the electrical and electronic product sector. The quantities of polymers to be traced are therefore potentially large.

The choice of polymers to be recycled is defined by their ability to be recycled, their inability to be sorted with current industrial sorting technologies and their chemical compatibility, market demand in terms of the volumes sought, and the potential quantities available in the waste (Fig. 7).

\subsubsection{Material recyclability}

The directive on waste defines recyclability as the ability to be removed from the end-of-life flow to be recycled. Recycling enables the production of secondary materials, or secondary raw materials, from an element of waste. This definition does not include the production of secondary materials as a substitute fuel.

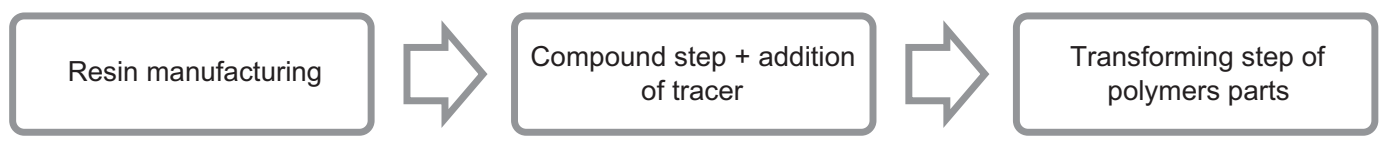

Fig. 3. Phases for tracer incorporation in the virgin material.

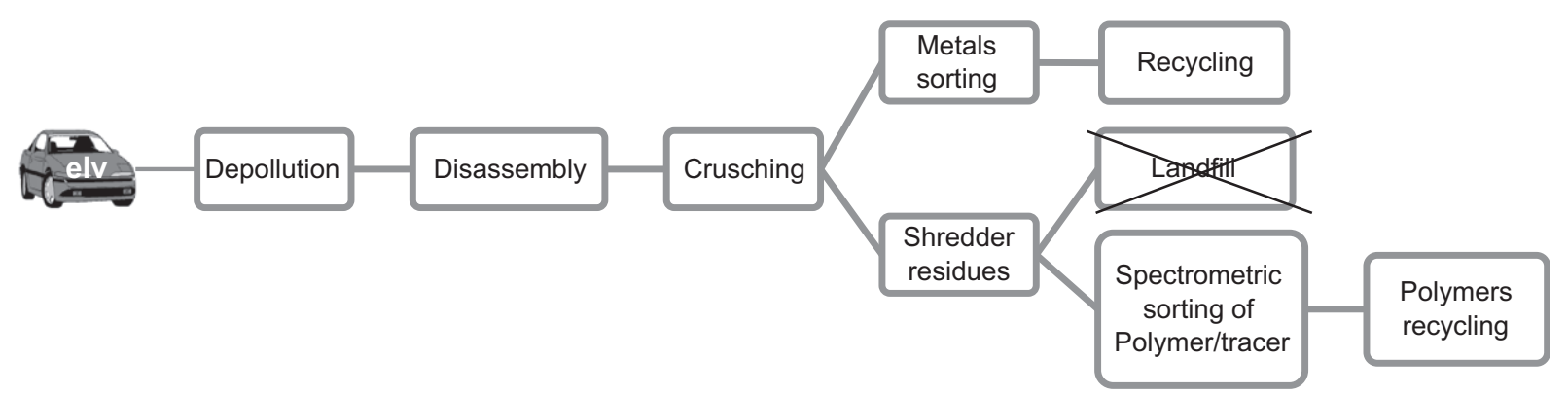

Fig. 4. Treatment phases for polymers traced for recycling and originating from end-of-life vehicles (elv). 


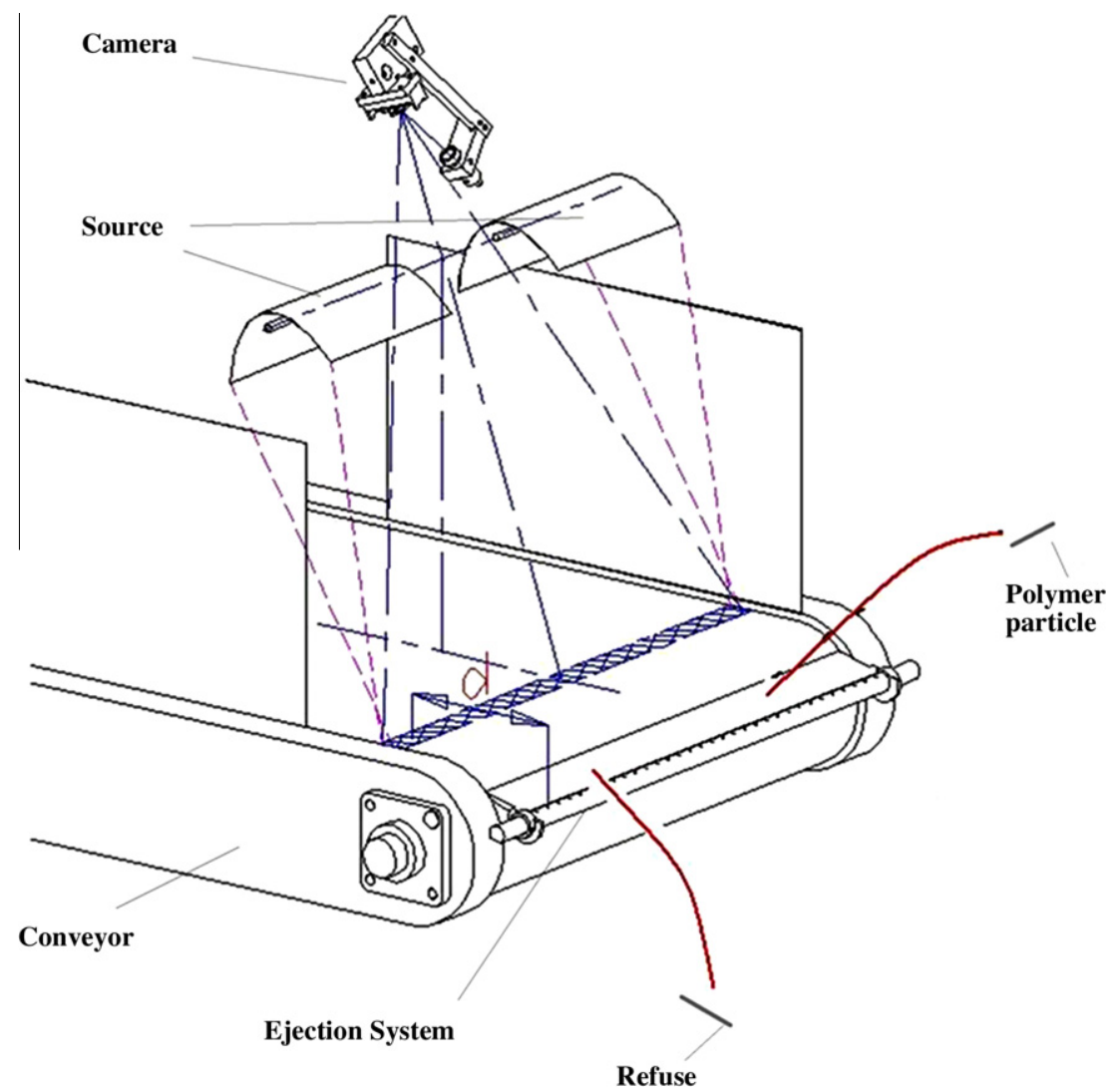

Fig. 5. Diagram of an automated spectrometric sorting machine (Pellenc).

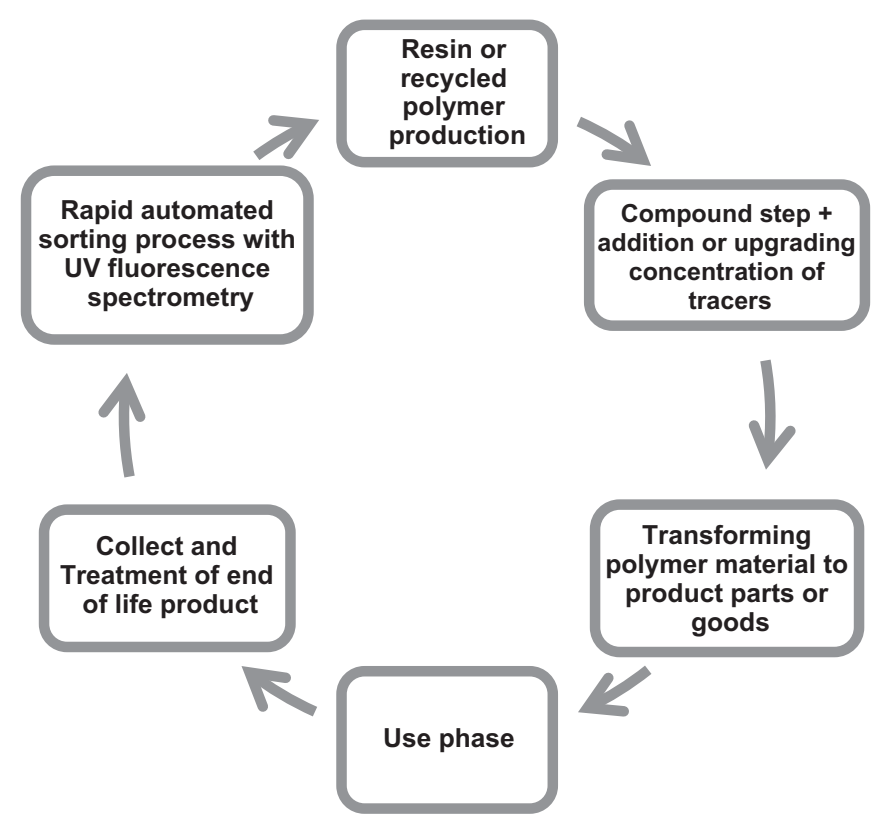

Fig. 6. Flow diagram of the life cycle of the traced polymers.

In the ISO standard on the recyclability and recoverability of vehicles (ISO standard 22628, 2002-02-15), recyclability is defined as the recovery of waste to produce products, materials or substances intended for their original purpose or for other purposes.

In this study, the recyclability of a polymer is defined as the ability of a material to produce a secondary raw material having the same purpose as its initial function, i.e. with mechanical prop- erties, a type of usage and an economic value close to those of the virgin material.

\subsubsection{The limits to existing sorting processes}

Electrostatic sorting, floating and sorting by NIR spectrometry are existing techniques that have not been validated for complex mixtures originating from product crushing (Table 1).

Densimetric sorting performs well when density differences represent 0.12 (Standard XP R10-402, 1996, Vehicle design in view of end of life recovery optimization - Road vehicles). For smaller differences or the cases where densities overlap, densimetric sorting is not possible on an industrial level. For example, this is the case for two types of material fractions often found in crushing residues from the automotive or electrical/household appliance/electronic sectors, such as PP $\left(0.8-0.96 \mathrm{~g} / \mathrm{cm}^{3}\right)$, PEHD $\left(0.94-0.95 \mathrm{~g} / \mathrm{cm}^{3}\right)$ and PEBD $\left(0.92-0.93 \mathrm{~g} / \mathrm{cm}^{3}\right)$ or PP-T20s $\left(1.04-1.06 \mathrm{~g} / \mathrm{cm}^{3}\right)$, HIPS (1.03$\left.1.05 \mathrm{~g} / \mathrm{cm}^{3}\right)$ and $\mathrm{ABS}\left(1.04-1.06 \mathrm{~g} / \mathrm{cm}^{3}\right)$. Moreover, these polymers are chemically incompatible with each other.

NIR spectrometric sorting enables the identification of lightcolored but not dark-colored polymers. Certain light-colored polymers are hard to identify with a high confidence index when associated with other polymers with a similar molecular structure. This is the case for example for ABS and ABS/PC or SAN.

\subsubsection{Market demand and potential quantities available}

The demand for polymers on the European market is divided into application sectors. The highest demand is for PE and PP in the packaging and automotive sectors and for electrical and electronic products. These three sectors are subjected to regulatory constraints such as the European waste directive, and therefore represent potentially large available quantities. Today the recycling rate is on average $22.5 \%$ in Europe, which is fairly low. It 


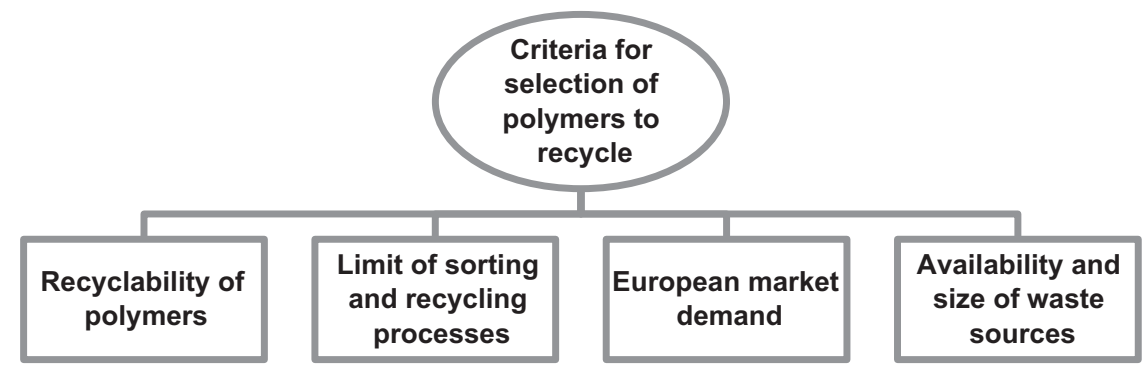

Fig. 7. Criteria for the choice of polymer materials to be recycled.

Table 1

The limits to existing sorting techniques.

\begin{tabular}{|c|c|c|}
\hline \multirow[t]{6}{*}{$\begin{array}{l}\text { Physico- } \\
\text { chemical } \\
\text { sorting }\end{array}$} & $\begin{array}{l}\text { Densimetric sorting } \\
\text { (Hwang Jiann-Yang, 1995) } \\
\text { (Altland et al., 1995) }\end{array}$ & (:) Low cost, industrial stage \\
\hline & & $\begin{array}{l}\text { (2) Not suited when densities are } \\
\text { similar }<0.12 \mathrm{~g} / \mathrm{cm}^{3}\end{array}$ \\
\hline & $\begin{array}{l}\text { Sorting by floating } \\
\text { (Fraunholcz, 2004) }\end{array}$ & (:) Low cost, \\
\hline & & $\begin{array}{l}\text { (:) Complex technique, } \\
\text { laboratory stage }\end{array}$ \\
\hline & $\begin{array}{l}\text { Triboelectric sorting (Hearn } \\
\text { and Ballard, 2004) }\end{array}$ & (:) Low cost, industrial stage \\
\hline & & $\begin{array}{l}\text { : Sensitive to humidity and } \\
\text { dust, does not sort complex } \\
\text { mixtures, limited to certain } \\
\text { polymers }\end{array}$ \\
\hline \multirow[t]{4}{*}{$\begin{array}{l}\text { Spectrometric } \\
\text { sorting }\end{array}$} & $\begin{array}{l}\text { NIR absorption (Huth- } \\
\text { Fehre et al., 1998) }\end{array}$ & $\begin{array}{l}\text { (:) Very rapid identification, } \\
\text { industrial stage }\end{array}$ \\
\hline & & $\begin{array}{l}\text { : Does not detect dark-colored } \\
\text { plastics and polymers with } \\
\text { similar formulation }\end{array}$ \\
\hline & $X$ rays (Biddle, 1999 ) & $\begin{array}{l}\text { :) Rapid, industrial } \\
\text { : Does not detect polymers, } \\
\text { with the exception of PVC/PET } \\
\text { separation }\end{array}$ \\
\hline & $\begin{array}{l}\text { UV fluorescence (Pascoe, } \\
\text { 2003) (Bart, 2006) }\end{array}$ & $\begin{array}{l}\text { :) Enables the detection of food } \\
\text { materials in the industrial stage } \\
\text { : No industrial sorting for } \\
\text { polymers, not very } \\
\text { characteristic spectra for } \\
\text { polymers }\end{array}$ \\
\hline
\end{tabular}

reaches $30 \%$ in the packaging sector, $10 \%$ in the automotive sector, and $9.5 \%$ in the electrical and electronic sector (PlasticsEurope, 2010). These rates vary considerably according to country.

The demand for recycled polymers is high, and is not satisfied in today's market. It is especially high for carmakers. With the Eco 2 label, the carmaker Renault has committed to using at least $5 \%$ of recycled plastics, and other manufacturers such as PSA, Toyota and BMW have adopted a similar approach.

The polymers that must be recycled in priority are those for which demand is high and which must satisfy specific applications in each industrial sector. These therefore include the polyolefins (PP, PEHD, and PEBD) common to all sectors, and styrenics (PS and ABS) and polyamides (PA66) for the automotive sector and for electrical and electronic products (Fig. 8). The table below (Table 2) summarizes the criteria for choosing materials to trace for recycling.

\subsection{Criteria for the choice of fluorescent tracers}

Constraints taken into account for the choice of tracers are fluorescence phenomena of polymers, attenuation phenomena due to certain additives incorporated into polymers and the requirements for polymers applications in automotive and electric-electronic sector.

\subsubsection{The limits to fluorescence phenomena}

Fluorescence is a light emission process visible during the spontaneous radiative relaxation of a chemofluorescent excited by the absorption of incident radiation.

This process thus takes place in two steps: the absorption of a photon by the fluorescent molecule (chemofluorescent), followed by the emission of a photon with lower energy by this same chemofluorescent

Fluorescence is often emitted at higher wavelengths than that of excitation radiation. In a linear excitation regime where the absorption coefficient does not depend on the incident intensity, the fluorescence yield, or Stern-Volmer factor, is defined by the relationship of the re-emitted light energy versus the incident energy absorbed.

Chemofluorescents are thus characterized by an excitation spectrum and a fluorescence spectrum. The distance between the two peaks of these two spectra is called the Stokes displacement. The spreading out of the absorption spectrum is due to the existence of the intermediate energy levels between the different electronic levels (Jablonski's diagram). The characteristics of the chemofluorescents are the quantic fluorescence yield (number of photons emitted/number of photons absorbed), which depends on the environment into which the chemofluorescent is added, the intensity of fluorescence and the fluorescence lifetime.

Certain phenomena can disturb fluorescence, and are referred to as quenching phenomena. Quenching of fluorescence is a decrease in the quantic yield of a chemofluorescent, and can be:

- Dynamic: with species such as halogens, amines, acrylamides, e.g. fluorinated, brominated, chlorinated additives.

- Static: formation of non-fluorescent complexes, e.g. interaction between the polymer or an additive with the chemofluorescent.

- Due to the attenuation of the light in the presence of colorants during either excitation or emission or during reabsorption, e.g. carbon black.

- Due to a high concentration of chemofluorescent which reabsorbs its own fluorescence.

The choice of tracers also depends on the fluorescence emissions of the matrixes, which have a fluorescence spectrum that is continuous but also has peaks depending on the excitation wavelengths (Gachkovskii, 1967). The fluorescence of polymers is mainly due to the carbon-carbon double bonds. One must also take into account the effect of the additives added to the polymers to color them, for example titanium dioxide and carbon black. 


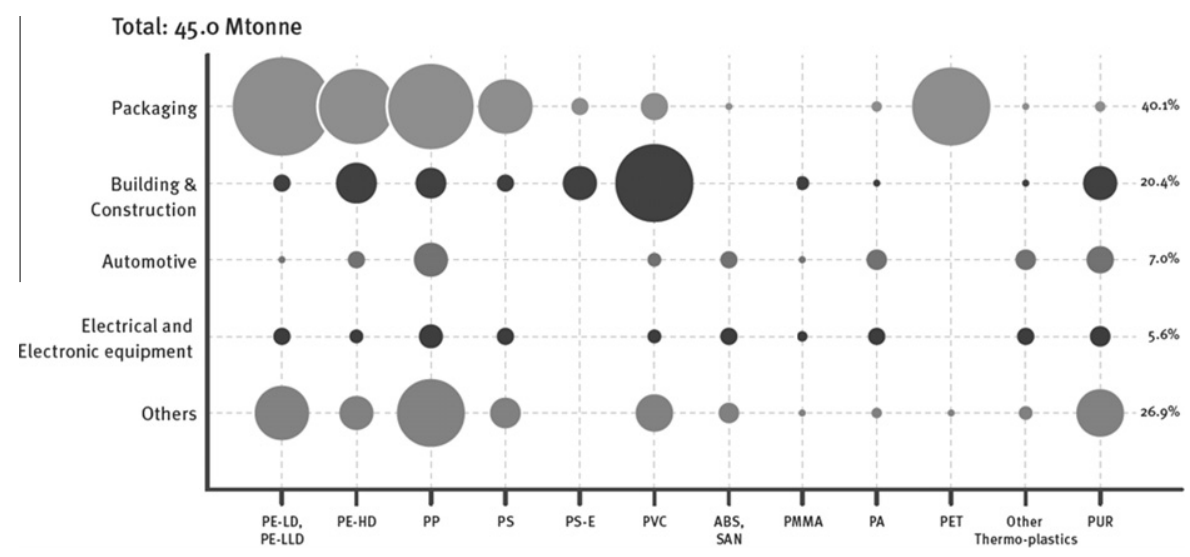

Fig. 8. Market demand breakdown by sector (PlasticsEurope, 2010).

Table 2

Summary of the criteria for choosing polymers to trace for recycling.

\begin{tabular}{|c|c|c|}
\hline \multicolumn{2}{|c|}{$\begin{array}{l}\text { Criteria for choosing polymer materials to } \\
\text { trace }\end{array}$} & Examples of polymers \\
\hline \multicolumn{2}{|c|}{ Recyclability } & Thermoplastic polymers \\
\hline \multicolumn{2}{|c|}{ Market demand } & $\begin{array}{l}\text { Polyolefins, Styrenics, } \\
\text { Polyamides }\end{array}$ \\
\hline \multicolumn{2}{|c|}{ Large potential quantities } & Polyolefins \\
\hline $\begin{array}{l}\text { Ability } \\
\text { to be }\end{array}$ & sorted & $\begin{array}{l}\text { Difficult to sort and } \\
\text { incompatible or having } \\
\text { different applications }\end{array}$ \\
\hline \multirow{3}{*}{$\begin{array}{l}\text { PP/PEBD, } \\
\text { PP/ } \\
\text { PEHD, }\end{array}$} & $\begin{array}{l}\text { PEHD/PEBD, PP-TD20/ABS, } \\
\text { PP-TD20/PS, ABS/PS, }\end{array}$ & \\
\hline & $\begin{array}{l}\text { Difficult to sort with current } \\
\text { technologies and compatible }\end{array}$ & $\mathrm{ABS} / \mathrm{SAN} / \mathrm{ASA}, \mathrm{PC}+\mathrm{ABS} / \mathrm{PC}$ \\
\hline & $\begin{array}{l}\text { Easy to sort with existing } \\
\text { technologies and incompatible }\end{array}$ & $\mathrm{PP} / \mathrm{ABS}, \mathrm{PP} / \mathrm{PS}, \mathrm{PE} / \mathrm{ABS}, \mathrm{PE} / \mathrm{PS}$ \\
\hline
\end{tabular}

\subsubsection{Industrial constraints}

In addition to the constraints described above, other constraints include health and safety, the environment, the cost, etc. The specifications for the tracers finally read as follows:

- must be non-toxic in compliance with the RoHS regulations,

- must not exceed $0.06 € / \mathrm{kg}$ of polymer,

- must improve detection and sorting techniques,

- must be chemically compatible with all of the components of the traced polymer,

- must have a good capacity to be detected despite the presence of pigments in the material or on its surface, carbon black and paint,

- must be compatible with the function of the polymer,

- must not modify the mechanical and aging properties of the material,

- must not interfere with the fluorescence emission of the polymers,

- must not deteriorate over time,

- no interferences between tracers in the case of combinations,

- low tracer concentrations $\mathrm{C}<1000 \mathrm{ppm}$, depending on the detection limits.

\subsubsection{Chemofluorescent families}

The choice of chemofluorescents, which is very wide, was limited to inorganic molecules and especially to two families, lanthanide-based and $\mathrm{Zn}$-based complexes. The special feature of these chemofluorescents is that when they are excited with UVs between
$300 \mathrm{~nm}$ and $400 \mathrm{~nm}$ they have a fluorescence in the visible light spectrum. These chemofluorescents enter into the composition of low consumption lamps and offer stable properties and good temperature resistance.

Lanthanides are normally found in the form of trivalent cations, except for europium, which has two forms, $2+$ et $3+$, and cerium $3+$ and $4+$. Lanthanides, after cerium, rarely have a degree of oxidation of $4+$. The absorption and emission of lanthanide ions originating from ff transitions are called "forbidden" transitions, meaning that the absorption and emission are very weak and slow. These problems are overcome by ion complexing with a ligand.

In inorganic chemistry, a complex is a polyatomic structure constituted of one or several cations (most often metallic) surrounded by several ligands which are molecules or ions that transfer a portion of their electronic density onto the cation, thus forming chemical bonds with the latter.

Lanthanide complexes can be lanthanides doped with lanthanide or metallic oxides doped with lanthanides. There are also lanthanide complexes doped with polymers and silica, used in electroluminescent diodes.

Yttrium oxide doped with Eu3 + ions makes it possible to obtain yttrium orthovanadate YVO4:Eu3 + or yttrium oxysulfide Y2O2S: Eu3+(Handbook of Chemistry and Physics, vol. 4, CRC Press, New York, 2007-2008 “Yttrium”, p. 41). These are luminophors used to produce the red color in cathode-ray tube televisions. The red color itself is produced by the de-excitation of europium atoms. Yttrium compounds can be doped with different lanthanide cations such as Tb3+(terbium) to achieve a green luminescence.

Barium magnesium aluminates doped with europium $\mathrm{Al} 2 \mathrm{Ba} 2 \mathrm{M}-$ g207: Eu2+, magnesium cerium terbium aluminate, and magnesium cerium aluminate are other possible chemofluorescents, used in the composition of Philips' low consumption lamps.

\subsection{Choice of source and detection system}

\subsubsection{Limiting factors}

The choice of the source is a predominant criterion with respect to the choice of detectors. The choice of sources is limited for certain UV wavelengths. Three criteria must be taken into account when choosing sources for an industrial application: the lifetime of the sources, the matching between the spectrum of the lamps and the excitation spectra of the tracers, and the power of the source per surface unit.

Lasers, diode lasers and LEDs (light emitting diodes) do not exist in all wavelengths. For example, LEDs do not exist for the spectral zone between 290 and $330 \mathrm{~nm}$ (Davitt et al., 2005). Xenon lamps have a continuous spectrum but with varying intensities depend- 

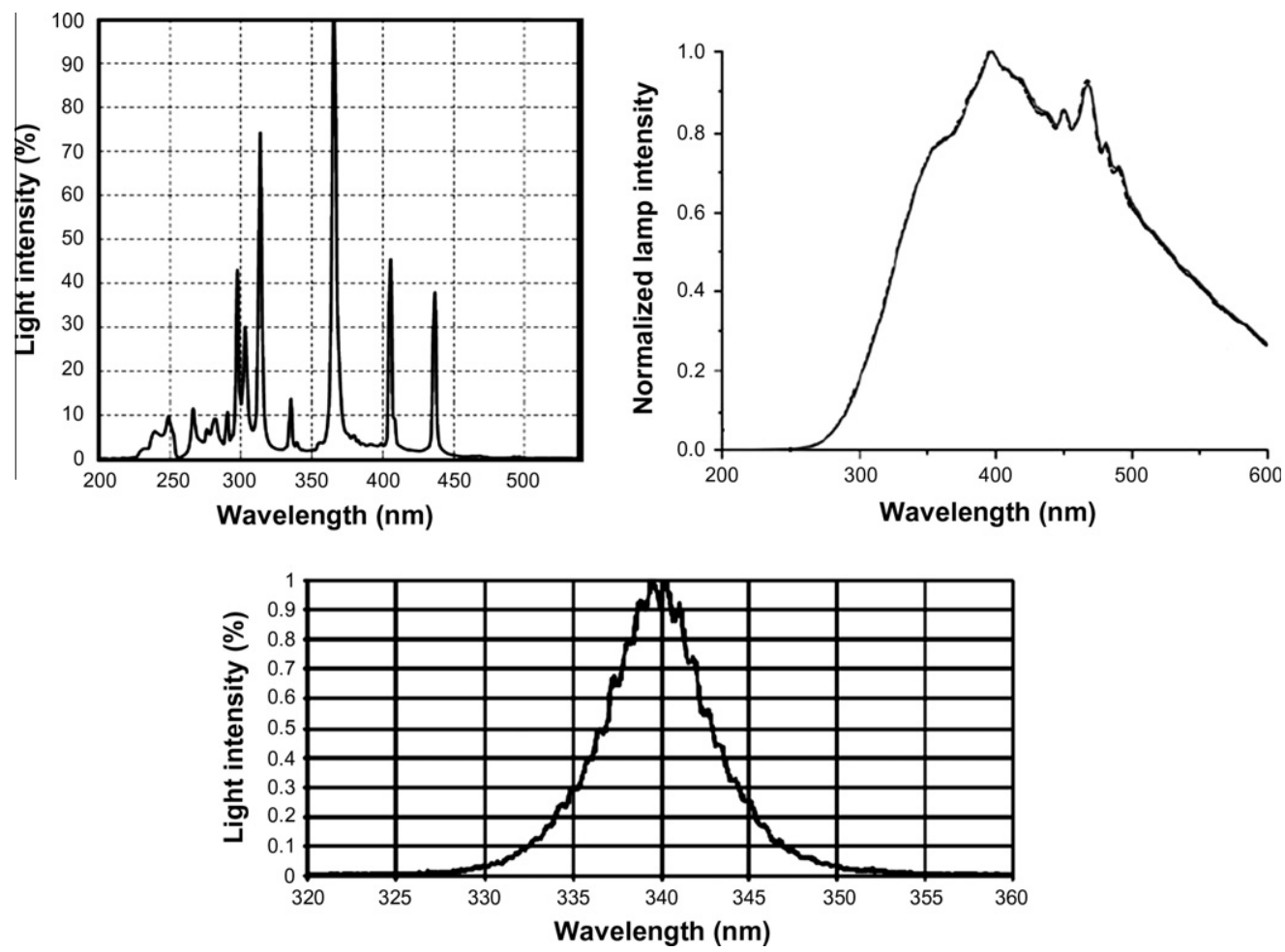

Fig. 9. (a) Spectrum of a mercury lamp, (b) spectrum of a Xenon lamp, (c) spectrum of a LED.

ing on the wavelengths, mercury lamps have a spectrum that is characteristic and discontinuous, and LEDs have a spectrum with a short bandwidth (Fig. 9a-c). The lifetime of lamps is shorter $(1000-4000 \mathrm{~h})$ than that of LEDs $(10,000 \mathrm{~h})$. The choice of tracers is thus dependent on the existence of the sources for industrial applications.

\subsubsection{Industrial constraints}

Criteria for choosing the detection and sorting mode:

- High yield and purity rate for the separated materials.

- Detection and sorting of crushed plastics with a grain size of roughly $20 \mathrm{~mm}$.

- Incident sources compatible with the excitation wavelengths of the tracers.

- Source lifetime and cost compatible with an industrial application.

- Detectors sensitive in the tracer fluorescence emission wavelengths in light-colored and black polymers and allowing a detection of $10 \mathrm{~ms}$.

- Filters allowing the detection of tracers with spectra with peaks that are close to each other.

\section{Results}

The results were achieved using two tracers, one a complex of rare earths doped with rare earths, and the other a complex of metallic oxides doped with rare earths. These tracers are referred to below as T1 and T2. The fluorescent wavelengths detected for their identification are respectively $615 \mathrm{~nm}$ and $525 \mathrm{~nm}$. Bibliographical research indicates that tracer $\mathrm{T} 1$ is potentially more stable and less influenced by its environment than tracer T2.

\subsection{Mixtures produced}

The tests were performed with a polypropylene matrix, colorless and colored with carbon black for the black color, and an ABS matrix colored with titanium dioxide. Two tracers were tested (Table 3 ). The first one had a red fluorescence and the second a green fluorescence. The mixtures are shown in the table below (Table 3). Tracer concentrations are higher with the polymer matrixes colored black than with the light-colored matrixes, because the carbon black limits the fluorescence emission in the matrix.

\subsection{Resistance of the mechanical properties before and after aging}

Specimens and plates were made from a masterbatch (a concentrate of tracers in a polymer). The latter was then diluted to $0.5 \%, 1 \%, 2 \%$ and $4 \%$ to reach a final concentration ranging between 25 and $250 \mathrm{ppm}$. Plates were painted to test paint adherence. The incorporation of tracers at a low concentration posed no problems.

\subsubsection{Method}

Standardized tests on the mechanical properties before and after aging were performed in order to verify that the incorporation of tracers at concentrations between 25 and $250 \mathrm{ppm}$ had no influence on the mechanical properties of the polymers. The PP parts were compared either bare or painted. ABS parts were compared bare. The parts were subjected to different types of aging (thermal, $\mathrm{UV}$, immersion in water, etc.). Comparisons were also carried out on aged and non-aged parts.

4.2.1.1. Characterization method for the mechanical properties. Traction: The uniaxial traction properties were measured using the testomeric M350-20CT instrument together with a $2000 \mathrm{kgf}$ force sensor and a mechanical extensometer. The tests were performed in compliance with standard ISO527-2: 1996 at a temperature of 


\begin{tabular}{|c|c|c|c|c|}
\hline & Reference & Tracer T1 Concentration (ppm) & Tracer T2 concentration (ppm) & $\mathrm{T} 1+\mathrm{T} 2$ Concentration (ppm) \\
\hline PP homopolymer + carbon black (black colorant) & 0 & 200 & & \\
\hline PP colorless copolymer & 0 & & 50 & \\
\hline ABS + TiO2 (white colorant) & 0 & & & 25 \\
\hline
\end{tabular}

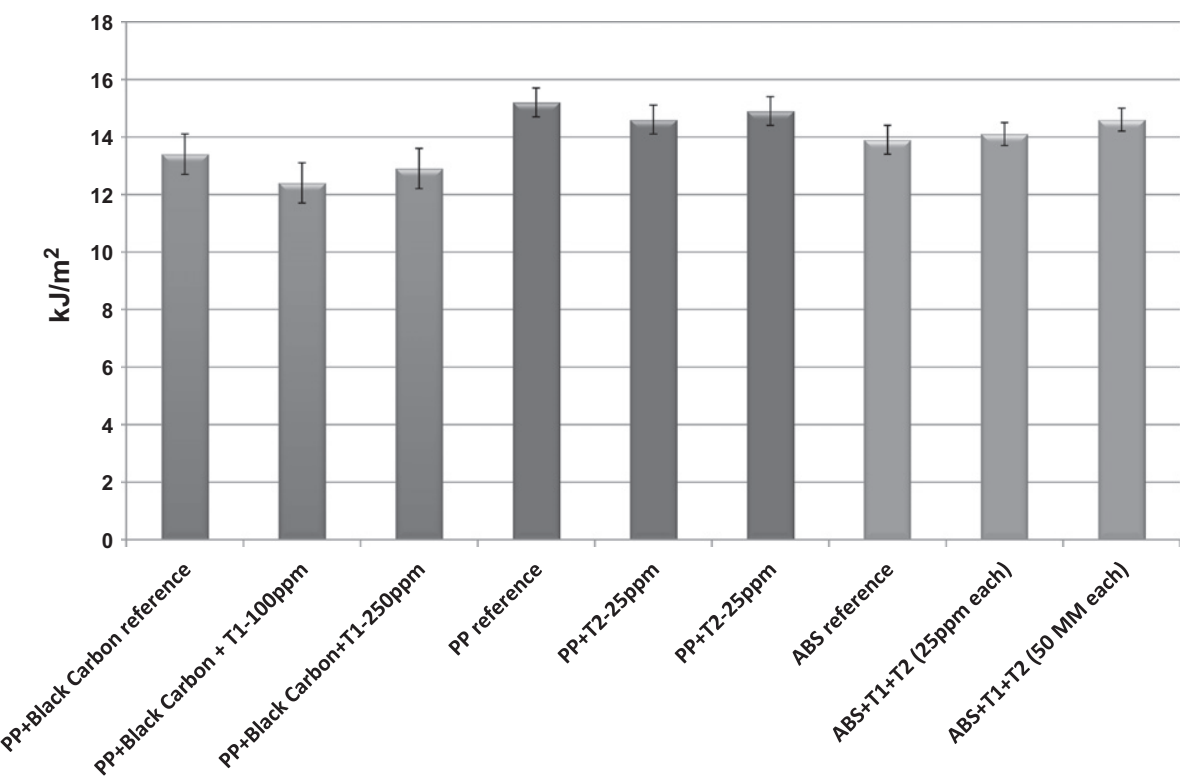

Fig. 10. Impact strength properties.

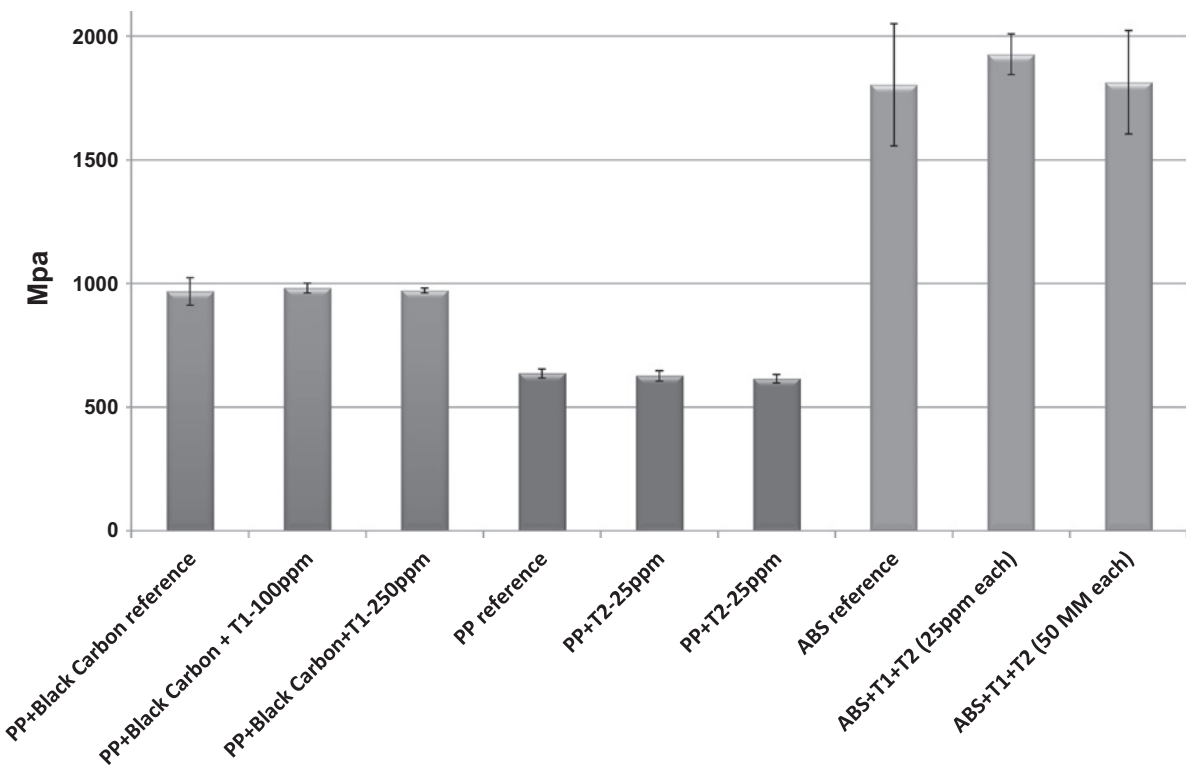

Fig. 11. Flexural Modulus properties.

$22^{\circ} \mathrm{C} \pm 2^{\circ}$. The specimens had a standard type $1 \mathrm{~A}$ size $(150 * 20 * 4 \mathrm{~mm})$. The Young modulus was measured on the first portion of the curve. The speed applied to measure strain at failure was $50 \mathrm{~mm} / \mathrm{min}$. For each configuration, 5 specimens were tested.

Flexure: Flexure was measured on the same 3-point bending instrument in compliance with standard ISO 178. The size of the specimens was standardized at $80 * 10 * 4 \mathrm{~mm}$. The spacing between the holders (space) was $64 \mathrm{~mm}$ in compliance with the standard (16 times the thickness of the specimen). Test speed was $2 \mathrm{~mm} /$ min for 5 specimens per configuration.

Impact strength: Impact strength was tested at $22^{\circ} \mathrm{C}$ using a ZWICK D7900 Type 5102-100/00 instrument in compliance with 


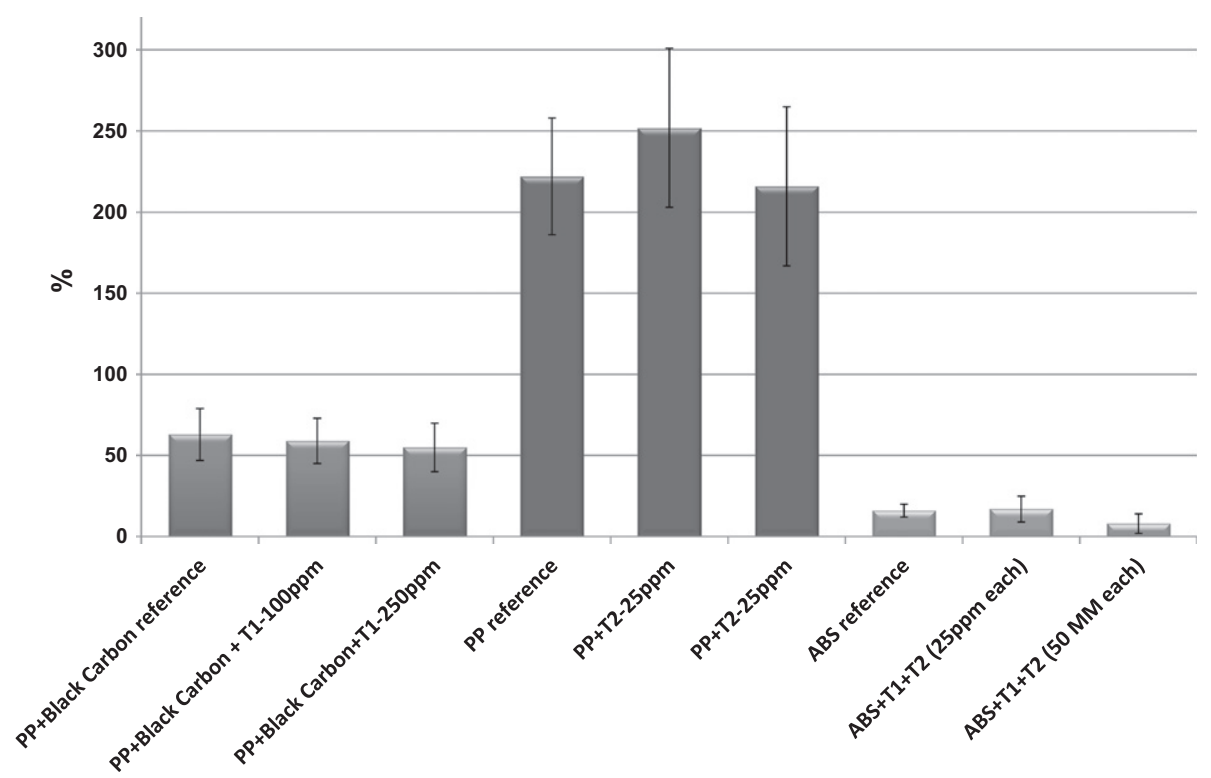

Fig. 12. Strain at Failure properties.

standard ISO179. A $2 \mathrm{~mm}$ slit was cut into the specimens (real section $8 * 4 \mathrm{~mm}$ ), and 10 specimens were tested per series.

4.2.1.2. Aging tests. The aging tests standardized for ABS are not the same as those for PP, since ABS has an inferior aging resistance and specific applications.

For the ABS: QUV (Accelerated Weathering testing): at $55^{\circ} \mathrm{C}$, under $340 \mathrm{~nm}$, test duration $400 \mathrm{~h}$.
For the PP: WOM (Weather-Ometer): as per D 27 1911/D, test duration $=2750 \mathrm{~h}$

\subsubsection{Results}

At the percentages used, in the PP and ABS tested, the tracers do not significantly modify properties such as traction, flexure, or impact strength, (Figs. 10-12). The mechanical properties of PP have been compared before and after aging test (Fig. 13). The losses of properties are similar between virgin PP and PP

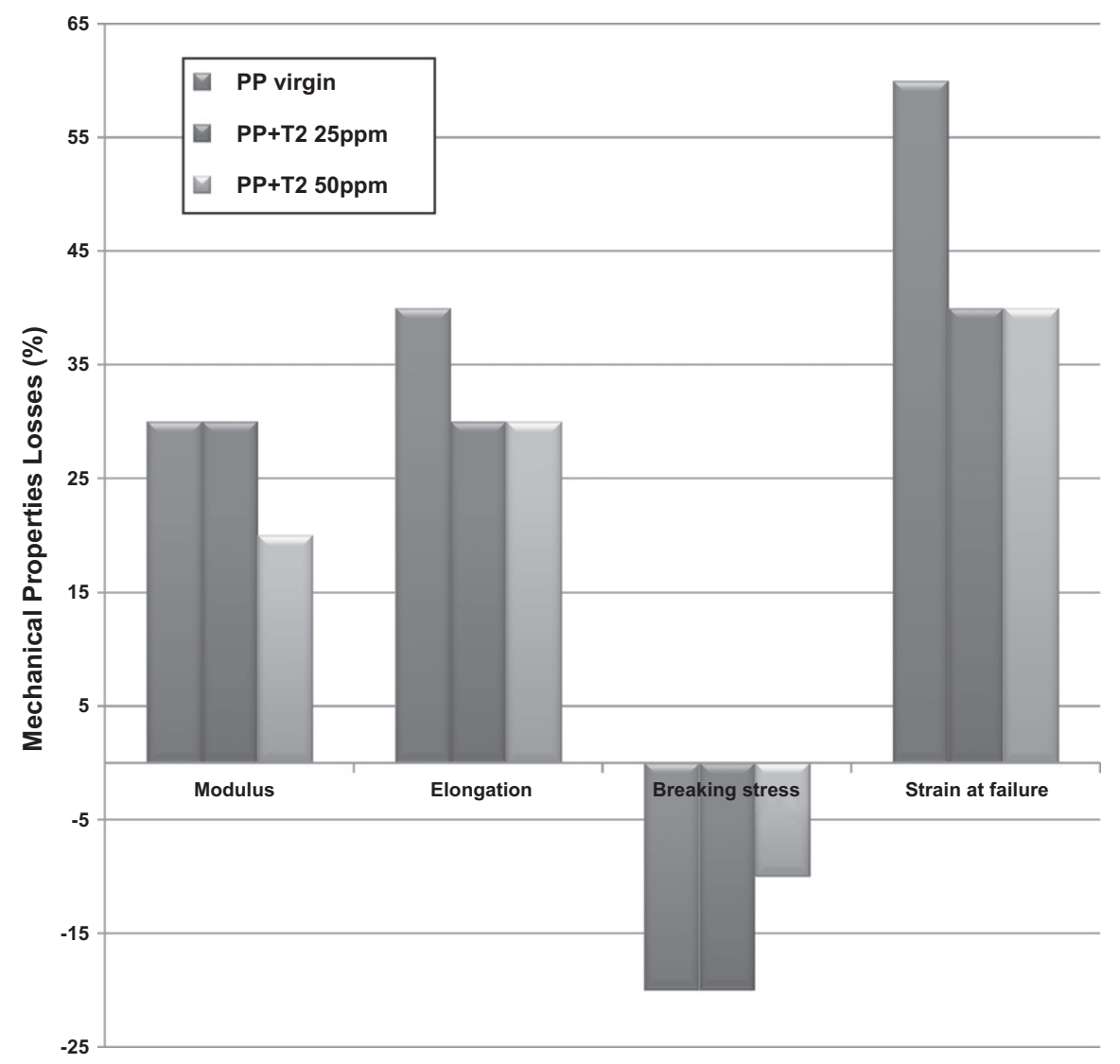

Fig. 13. Loss of mechanical properties after aging test 


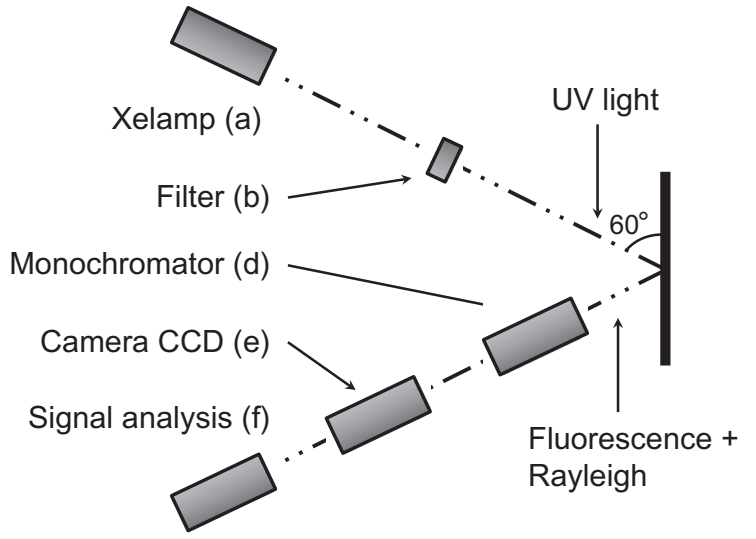

Fig. 14. The source (a) is a $150 \mathrm{~W}$ Xe lamp, emitting from 240 to $850 \mathrm{~nm}$. The beam passes through a low-pass filter (b) with a $370 \mathrm{~nm}$ cutoff wavelength, thus only UV light reaches the sample with a 60 degree incidence angle. The light reflected on the sample (c) is composed of fluorescence lines and Rayleigh scattering. The reflected beam enters an emission monochromator (d) and is then detected by a CCD camera device (e) and computed by a signal analysis system (f).

with tracer. For example the loss of elongation properties is $40 \%$ for virgin PP before and after aging tests and 30\% for PP with tracers.

Likewise, properties such as the adherence, brilliance, and color of the painted PP are not modified by the presence of the tracers.

\subsection{Detection tests before and after aging}

The objective was to identify the UV fluorescence of the chosen tracers in different polymer matrixes containing two colorants and after standardized aging tests.

\subsubsection{Optical system and experimental conditions}

The detection system included a Xenon source, a low-pass filter and an emission monochromator to analyze a fluorescence wavelength specific to each of the tracers, a CCD camera to detect the system, and a data acquisition and processing system (Fig. 14).

Experimental conditions:

The main criteria to validate the measurements were:

- To eliminate the Rayleigh scattering with a filter.

- To search for a linearity perimeter between the intensity of the signal and concentration.

- To determine the excitation and emission wavelengths.
Table 4

Tracer detection results before and after aging.

\begin{tabular}{llll}
\hline & $\mathrm{PP}+\mathrm{NC}+\mathrm{T} 1$ & $\mathrm{PP}$ colorless PP $+\mathrm{T} 2$ & $\mathrm{ABS}+\mathrm{TiO} 2+(\mathrm{T} 1+\mathrm{T} 2)$ \\
\hline Reference & 0 & 0 & 0 \\
$\mathrm{~T} 1$ & $\mathrm{X}$ & $\mathrm{X}$ & $\mathrm{X}$ \\
$\mathrm{T} 2$ & & $\mathrm{X}$ & 0 \\
\hline
\end{tabular}

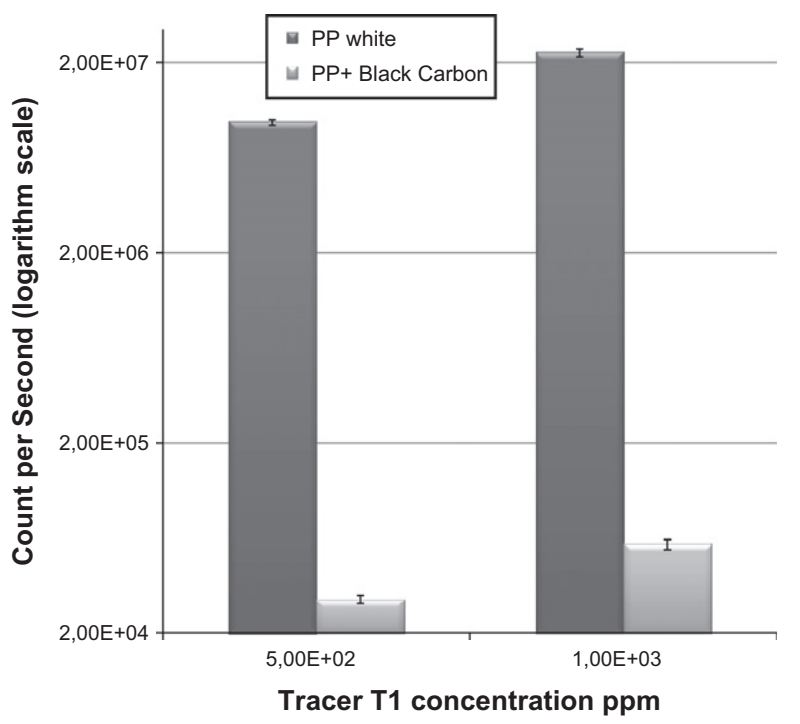

Fig. 16. Quenching phenomenon due to the presence of carbon black at concentration of $5 \%$ in a polypropylene matrix with a concentration of tracer $n^{\circ} 1$ between 500 and $1000 \mathrm{ppm}$.

- To validate an excitation wavelength allowing discrimination between the fluorescence of the tracers and that of the matrix.

- The intensity of the tracer's fluorescence signal must be greater than three times the standard deviation of that of the white (matrix signal) in order to be validated.

Experiment protocol:

- 20 Different surface measurements per sample, on aged samples. The measurement was only made on the exposed surface.

- Integration time $0.01 \mathrm{~s}$.
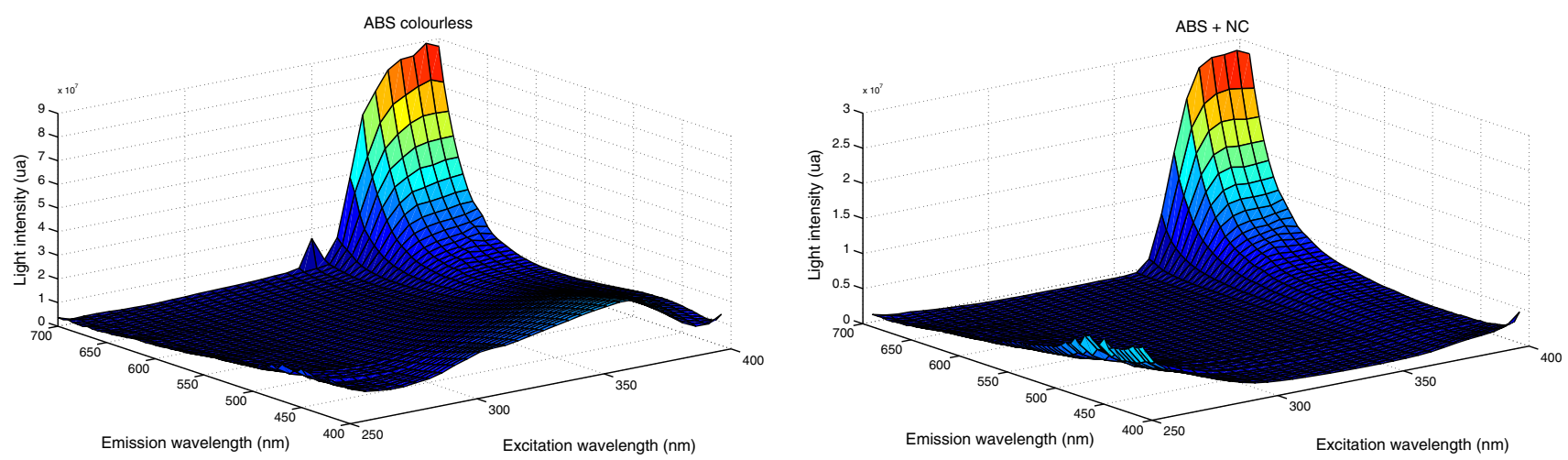

Fig. 15. Fluorescence of the ABS without and with carbon black. 


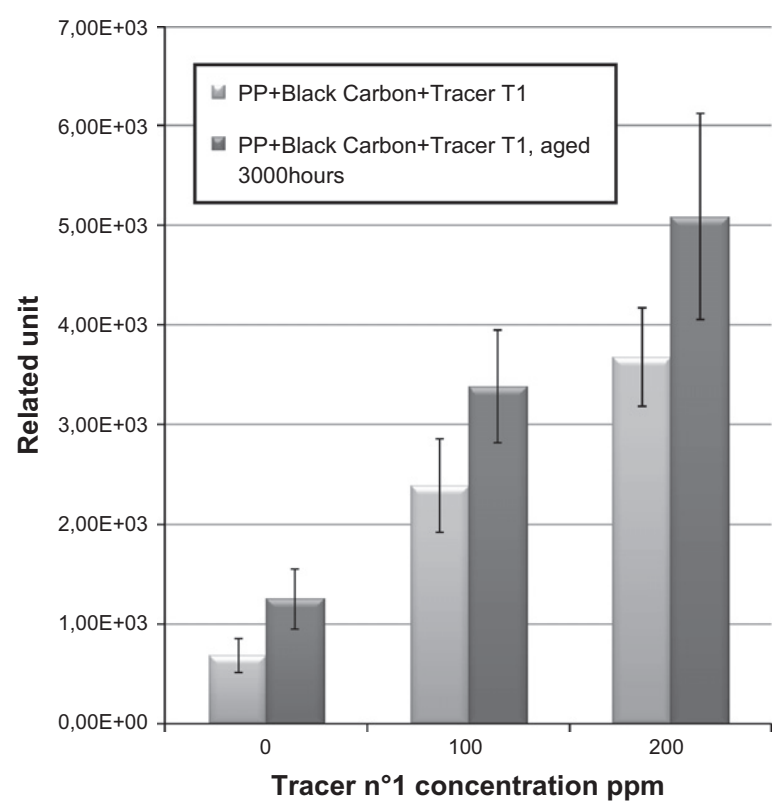

Fig. 17. Intensity of the fluorescence signal of tracer $\mathrm{T} 1$ in black PP before and after aging.

- Measurement uncertainty calculation.

- The tests were validated by 2 test campaigns and the results are reproducible.

The relative uncertainty of the measurements due to the instrument was less than $1 \%$, and was determined by carrying out 20 measurements on the same surface. The relative standard deviation of the measurements increases when tracer concentration decreases.

The tracer detection window was optimized with preliminary tests.

3D spectra were made on powder tracers and then on polymer samples containing different tracer concentrations. The polymer matrixes have a continuous fluorescence in the visible spectrum, but different signal intensities depending on the wavelength (Fig. 15). The fluorescence of the matrix is not a limiting factor for tracer detection for concentrations from 500 to $1000 \mathrm{ppm}$.

For lower concentrations, the fluorescence of the matrix must be taken into account for the signal-noise to be sufficient, in order to have a confidence index greater than $95 \%$.

The excitation wavelength was thus determined, taking into account the spectral zone common to each tracer and matrix in order to optimize the tracers' fluorescence signal. The detection characteristics are the wavelengths of excitation and emission fluorescence, the monochromator slit width for a time of $10 \mathrm{~ms}$. The detection of the polymer-tracer systems was then validated for excitation wavelengths between 250 and $400 \mathrm{~nm}$. Measurements of the white (matrix signal) (see Fig. 15) and measurements with different tracer concentrations were performed. The most favorable windows are located between 300 and $370 \mathrm{~nm}$. These tests were carried out before and after aging of the samples.

\subsubsection{Tracer detection results before and after aging}

The results are validated whatever the predefined concentrations (Table 4).

( $\mathrm{X}=$ identification, $0=$ no signal detected):

Tracer T1 was identified in the black PP homopolymer and the white ABS. Tracer T2 was identified in the colorless PP copolymer but not in the ABS.

The measurements confirmed the tracer concentrations in the polymers for the black PP homopolymer and the colorless PP

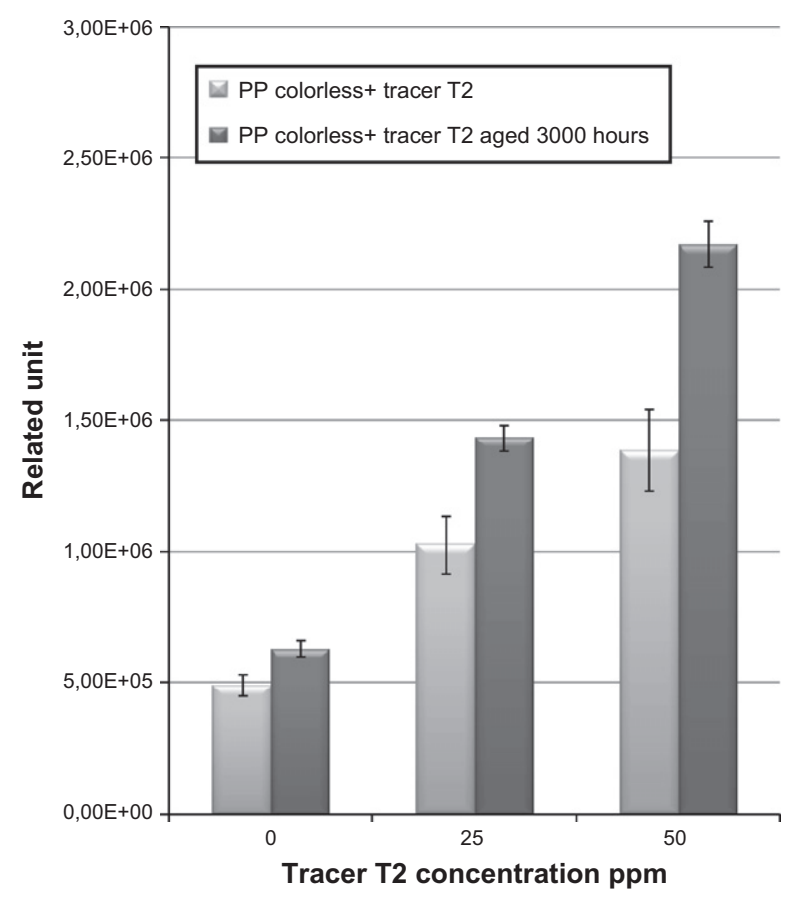

Fig. 18. Intensity of the fluorescence signal of tracer $T 2$ in colorless PP before and after aging.

copolymer, and the standard deviations were less than the signal difference measured for each concentration.

\subsubsection{Quenching phenomena}

Three tracer fluorescence quenching phenomena were observed. This signal attenuation may be due to the interaction between:

- Colorants (carbon black and TiO2) and polymer.

- Tracers when they are combined.

- Polymers and tracers.

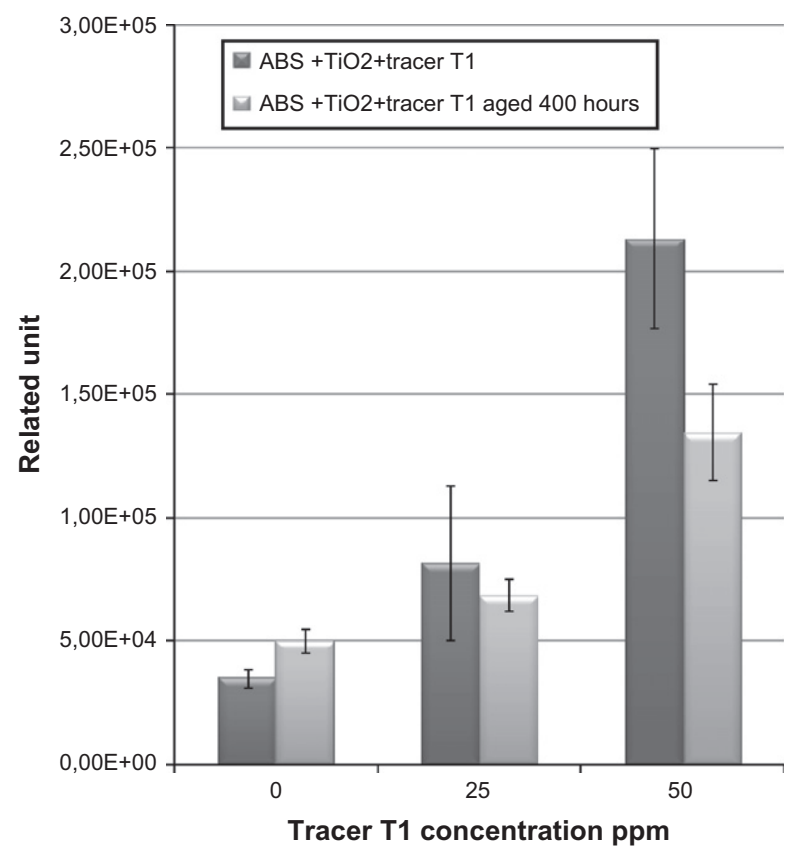

Fig. 19. Fluorescence signal of tracer $T 1$ in $A B S$ colored white before and after aging. 
Tracer T1 is detected in the polypropylene colored black and the ABS colored white. The signal is attenuated by the presence of the white and black colorants, but the signal-noise ratio is sufficiently high for detection to be positive.

Additional tests showed that the order of magnitude of the tracer signal attenuation for PP colored white and colored black is a factor of 350 (Fig. 16).

No quenching phenomenon was observed with the combination of tracers T1 and T2 in PP colored white and black.

A quenching phenomenon was observed when tracer T2 was incorporated in the ABS colored white, whereas it was perfectly detected in the colorless polypropylene, and additional tests showed that it was also detected in PP colored black and white.

In conclusion, the signal from tracers $\mathrm{T} 1$ and $\mathrm{T} 2$ incorporated in PP is attenuated but still detected in the presence of black and white colorants. There is no interaction of tracers T1 and T2 when they are combined in PP. Tracer T2 is not detected when incorporated in $\mathrm{ABS}$.

\subsubsection{Effects due to aging}

It would seem that the effect of aging on the surface of the two polymers tested is different. The signal of the two tracers is more intense after aging of the PP. The detection signal is less intense for the ABS (Figs. 17-19). Since the aging was under UV light, there are probably oxidation mechanisms occurring on the matrixes that modify their surface properties. When one visually examines the surface condition of the two matrixes with and without tracer, the PP tends to whiten and the ABS tends to yellow strongly.

\section{Conclusion}

The concept of tracing polymers to enable their recycling responds to a real need to improve the recyclability of black-colored polymers with similar densities used in automotive and Electrical and Electronic Equipment products. The potential quantities of these materials are considerable and available, and correspond to a market demand for recycled materials fueled by regulations on waste treatment and the use of recycled materials.

The addition of tracers into polymer matrixes does not modify their mechanical properties at percentages lower than $250 \mathrm{ppm}$. The two polymers tested can be identified by a specific tracer. One of the tracers is not detected in ABS due to a quenching phenomenon. The minimum concentrations detected range from 25 and $100 \mathrm{ppm}$ and are compatible with the REACH regulation. The detection of black polypropylene was successful. The tracers are stable after aging tests. For the incorporated concentrations, the signal measured is proportional to the concentration. It is therefore possible to detect tracer concentrations in the polymers and thus top up the tracer concentration in recycled polymers.

Further works should be conducted on the determination of minimum detectable concentrations by a detection pilot system. A standard process should be proposed for the addition of tracers in polymer candidates for recycling.

This tracing technology can be applied to other materials whose sorting is currently unsatisfactory, for example to sorting different types of glass.

\section{Acknowledgments}

We would like to thank the partners who actively contributed to this project: Claude Lambert from the Tracing Technologies company who selected and supplied the tracers, the Rhône Alpes Region, which financed the detection equipment, Itech who carried out the tests on the mechanical properties of the polymers before and after aging, POAE and the SEB Group who prepared the masterbatches and samples, and the Pole National de Traçabilité, who ensured the project coordination. We also thank the Rhône Alpes Innovation Agency for having followed this Project with interest.

\section{References}

Ahmad, S.R.A., 2004. New technology for automatic identification and sorting of plastics for recycling. Environmental Technology 25 (10), 1143-1149.

Altland, B.L., Cox, D., Enick, R.M., Beckman, E.J., 1995. Optimization of the highpressure, near-critical liquid-based microsortation of recyclable post-consumer plastics. Resources, Conservation and Recycling 15, 203-217.

Bart, J.C.J., 2006. Plastics Additives: Advanced Industrial Analysis. IOS Press, p. 78. Bayer, 1994. Method for Identification of Plastics, Patent US5329127A.

Bezati, F., Froelich, D., Massardier, V., Maris, E., 2010. Addition of tracers into the polypropylene in view of automatic sorting of plastic wastes using X-ray fluorescence spectrometry. Waste Management 30, 591-596.

Biddle, M.B., Dinger, P., Fisher, M.M., 1999. An overview of recycling plastics from durable goods: challenges and opportunities, in: IdentiPlast II Conference.

BIR, 2009. Study on the environmental benefits of recycling, http://www.bir.org/ assets/Documents/publications/brochures/BIR_CO2_report.pdf.

British Petroleum Company, 1993. Method of Identifying Polymer Materials, Patent GB2264558A.

Davitt, K., Song, Y.K., Patterson III, W.R., Nurmikko, A.V., 2005. 290 and 340 nm UV LED arrays for fluorescence detection from single airborne particles. Optics Express 13 (23), 9548.

Eisenreich, N., Kull, H., Thinnes, E., 1992. Waste management of energetic materials and polymers, in: 23rd Int. Annu. Conf. ICT, Karlsruhe, 59/1.

Fraunholcz, N., 2004. Separation of waste plastics by froth flotation-a review, Part I Original research article. Minerals Engineering 17 (2), 261-268.

Froelich, D., Maris, E., Haoues, N., Chemineau, L., Renard, H., Abraham, F., Lassartesses, R., 2007a. State of the art of plastic sorting and recycling: feedback to vehicle design. Minerals Engineering 20 (9), 902-912.

Froelich, D., Maris, E., Massardier, V., Etat de l'art technico-économique sur les procédés et techniques d'incorporation de traceurs dans des matériaux polymères, en vue du tri automatisé des déchets plastiques des produits hors d'usage. Report No. 05-0907/1A, 2007, RECORD, French Industry-University Cooperative Research Network on Waste.

Gachkovskii, V.F., 1967. Universal fluorescence of polymers. Journal of Structural Chemistry.

Hearn, G.L., Ballard, J.R., 2004. The use of electrostatic techniques for the identification and sorting of waste packing materials. UK, Resources Conversation \& Recycling 44, 91-98.

Huth-Fehre, T., Feldhoff, R., Kowol, F., Freitag, H., Kuttler, S., Lohwasser, B., Oleimeulen, M., 1998. Remote sensor systems for the automated identification of plastics. Journal of Near Infrared Spectroscopy 6, A7-A11.

Hwang Jiann-Yang, 1995. Separation of Normally Hydrophobic Plastic Materials by Froth Flotation, Patent US5377844.

Lambert, C., Hachin, J.M., 2004. Method for Authentication by Chemical Marking or Tracing of an Object or a Substance, Patent WO2004040504.

Lambert, C., Hachin, J.M., 2010. Method for Automatically Identifying a Material or an Object, Patent WO2010012892A2.

Lambert, C., Hachin, J.M., Method for Identifying a Substance or Object Using a Plurality of Vectors, 2010, Patent US2010089804A1.

Millet D., 2003. Intégration de l'environnement en conception: Entreprises et Développement Durable, édition Hermes Science Publishing, 230p.

Pascoe, R.D., 2003. Sorting of plastics using physical separation techniques. Recycling and reuse of waste materials. in: Proceedings of the International Symposium, pp. 173-188.

PlasticsEurope, The compelling facts about plastics, An analysis of plastics production, demand and recovery for 2009 in Europe, Ed. PlasticsEurope, 2010, EuPC, EuPR, EPRO.

Reuter, M.A., van Schaik, A., Ignatenko, O., de Haan, G.J., 2006. Fundamental limits for the recycling of end-of-life vehicles. Minerals Engineering 19 (5), 433449.

Simmons, B.A., Overton, B.W., Viriot, M.-L., Ahmad, S.R., Squires, D.K., Lambert, C., 1998. Fluorescent tracers enable automatic identification and sorting of waste plastics BP \& R. British plastics and rubber, no JUN, pp. 4-12.

Tonnelier, P., Millet, D., Richir, S., Lecoq, M., 2007. Is it possible to evaluate the recovery potential earlier in the design process? Proposal of a qualitative evaluation tool. Journal of Engineering Design (JED) 16 (3), 297-309. 